3. Gattinoni L, Pesenti A, Mascheroni D, Marcolin R, Fumagalli R, Rossi F, et al. A low-frequency positive-pressure ventilation with extracorporeal $\mathrm{CO} 2$ removal in severe acute respiratory failure. JAMA. 1986;256:881-6.

4. Willms DC, Watchel TL, Daleiden AL, Dembitsky WP, Schibanoff JM, Gibbons JA. Venovenous extracorporeal life support in trau- matic bronchial disruption and adult respiratory distress syndrome using surface-heparinized equipment: case report. J Trauma. 1994; 2:252-4.

5. Michaels AJ, Schriener RJ, Kolla S, Awad SS, Rich PB, Reickert C, et al. Extracorporeal life support in pulmonary failure after trauma. J Trauma. 1999;4:638-45.

\title{
Reduction pneumoplasty for a giant right upper lobe bulla causing massive bilateral lung compression
}

\author{
Timothy L. Van Natta, MD, ${ }^{a}$ and Mark D. Iannettoni, MD, MBA, ${ }^{\mathrm{b}}$ Torrance, Calif and lowa City, la
}

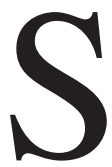

urgical therapy has been used for bullous emphysema since the mid-20th century. The best surgical candidates are often those with giant pulmonary bullae rather than those with diffuse disease. Several series describe selection criteria, techniques, and outcomes pertaining to the excision of giant bullae. ${ }^{1-3}$ In one report, the term "reduction pneumoplasty" was coined to denote giant bulla excision, and the accompanying review of 22 case series identified three harbingers of success. ${ }^{4}$ These involve the bulla size, degree of associated lung compression, and preoperative forced expiratory volume in 1 second $\left(\mathrm{FEV}_{1}\right)$. We present a patient with an enormous unilateral bulla compressing most of the right lung and much of the left lung. Bulla resection produced marked functional improvement and increased $\mathrm{FEV}_{1}$.

\section{Clinical Summary}

A 44-year-old foundry worker presented with progressive dyspnea and cough. Physical activity tolerance had deteriorated. Medical and family histories were unremarkable. He was exposed at work to airborne sand and metal dust. He regularly smoked marijuana and 2 to 3 daily cigarettes. Examination showed a chronically ill-appearing man with dyspnea on minimal exertion. Hyperresonant percussion notes were present over both hemithoraces, and breath sounds were diminished bilaterally. There were no stigmata of cor pulmonale. Chest radiograph was initially interpreted as showing large bilateral hydropneumothoraces (Figure 1), and he was referred to the University of Iowa Hospitals and Clinics for

\footnotetext{
From the Department of Surgery, Harbor-UCLA Medical Center, ${ }^{a}$ Torrance, Calif; and Department of Cardiothoracic Surgery, ${ }^{\mathrm{b}}$ University of Iowa, Iowa City, Ia.

Received for publication Jan 12, 2007; accepted for publication Feb 7, 2007.

Address for reprints: Timothy L. Van Natta, MD, Harbor-UCLA Medical Center, Department of Surgery, 1000 West Carson Street, Box 42, Torrance, CA 90509 (E-mail: timothy.vannatta@gmail.com).

J Thorac Cardiovasc Surg 2007;133:1674-5

$0022-5223 / \$ 32.00$

Copyright $\odot 2007$ by The American Association for Thoracic Surgery doi:10.1016/j.jtcvs.2007.02.010
}

treatment. Computed tomographic (CT) scan interpretation suggested bilateral giant bullous lung disease with air-fluid levels and extensive pulmonary compression (Figure 1). Alpha-1-antitrypsin level and complete blood count were normal. Forced vital capacity was $1.9 \mathrm{~L}$ and $\mathrm{FEV}_{1}$ was $1.4 \mathrm{~L}$, or $37 \%$ and $38 \%$ of predicted, respectively. Antibiotics and bronchodilators were prescribed. Given the patient's continued dyspnea, he was referred for surgical evaluation. Bullae resection through median sternotomy was advised.

Sternotomy was performed under general anesthesia, with a double-lumen endotracheal tube in place. A division of the anterior bulla wall occurred on sternal entry. Progressive left pulmonary reexpansion occurred, and that lung lacked overt emphysematous features. The bilateral seropurulent fluid was evacuated. Gram stain was negative. Isolated left pulmonary ventilation provided ample oxygenation, facilitating right lung evaluation and reduction pneumoplasty. A single, huge right upper lobe bulla had compressed the majority of the right lung and crossed beneath the sternum to produce marked compression of the left lung. This bulla had a narrow base, 3 to $4 \mathrm{~cm}$ diameter, off the apex. An Endo-GIA stapler with 3.5-mm staples (United States Surgical Corp, Norwalk, Conn) reinforced with Peri-Strips Dry (Synovis Surgical Innovations, St Paul, Minn) was used to excise the bulla and seal the underlying lung. A thin fibrinous rind around the right lung was easily excised. This produced good expansion of all lobes and obviated the need for right pleural tent creation. Thoracostomy tubes were placed, and the sternotomy was closed. Recovery was uneventful. Pleural fluid cultures were negative. Pathologic analysis indicated pleural inflammation and emphysema. At his second clinic follow-up 2.5 months later (Figure 2), the patient reported substantially improved exercise tolerance. Objectively, $\mathrm{FEV}_{1}$ improved from $1.4 \mathrm{~L}$ preoperatively to $3.5 \mathrm{~L}$ postoperatively (38\%-93\% of predicted, respectively).

\section{Discussion}

A comprehensive 1996 review of surgery for giant bullous emphysema concluded that three features portend success: bulla size exceeding one third of 1 hemithorax, marked compression of adjacent lung tissue (demonstrated by $\mathrm{CT}$ scan), and preoperative $\mathrm{FEV}_{1}$ less than $50 \%$ predicted. ${ }^{4}$ Our patient met all three criteria. Despite tremendous bilateral lung compression, the nonbullous 


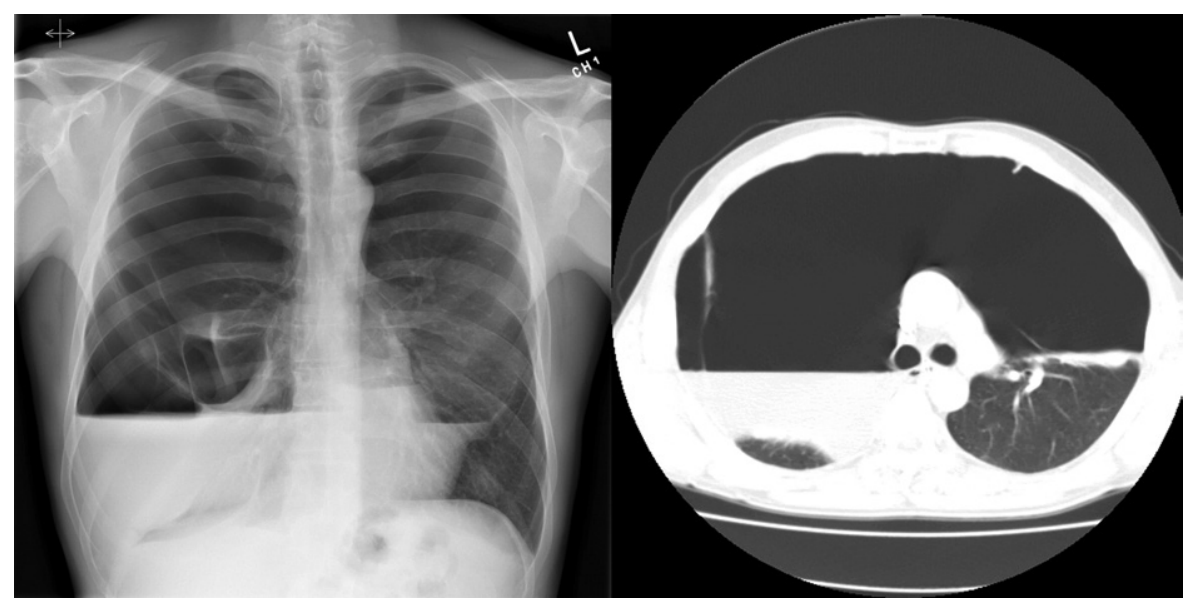

Figure 1. Preoperative posteroanterior chest radiograph and CT scan showing giant pulmonary bulla with air-fluid levels and bilateral lung compression, right greater than left.

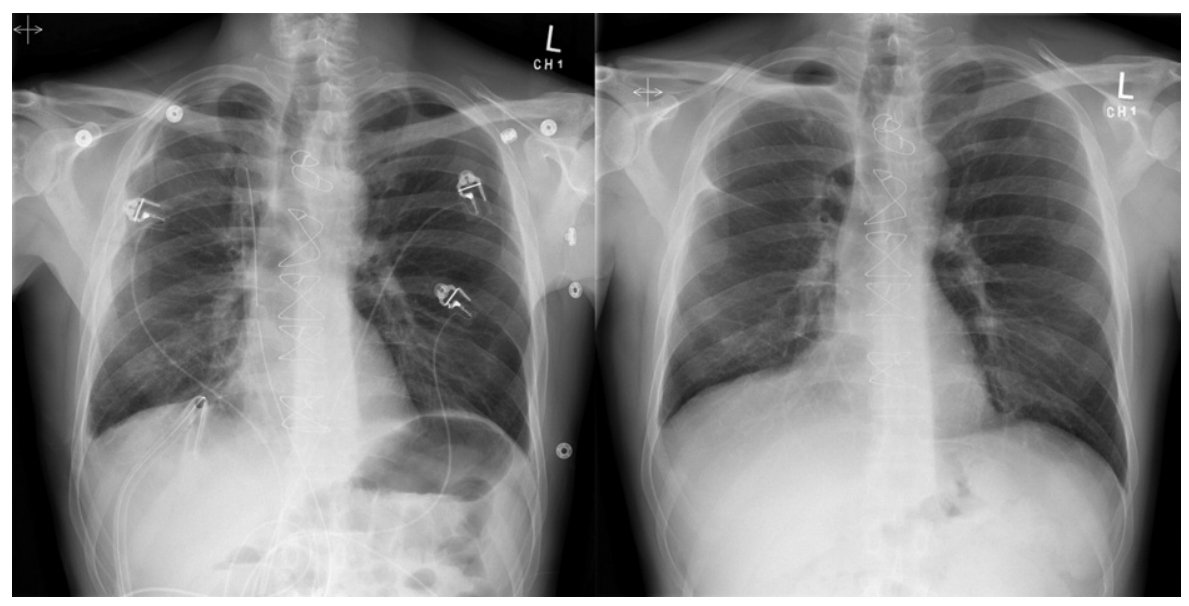

Figure 2. Posteroanterior chest radiography images immediately and $\mathbf{2 . 5}$ months postoperatively showing complete left lung and near-complete right lung reexpansion after giant bulla resection.

lung tissue appeared relatively well preserved on the CT scan. We addressed the bullous disease by median sternotomy, commonly used for lung volume reduction surgery. In a recent series of 43 patients undergoing giant bulla excision, median sternotomy was used in 25 cases. ${ }^{3}$ The unilateral bulla in our patient might have been amenable to excision through a right lateral thoracotomy or video-thoracoscopic approach. However, it was believed preoperatively that bilateral bullae were present, favoring median sternotomy. A buttressed bullectomy staple line has been advocated, given the high risk of persistent postoperative air leak. ${ }^{3}$ Staple line reinforcement was used in our case. It has also been noted that the underlying lung may not fully reexpand after bullectomy and that consideration must be given to resulting space issues. ${ }^{3}$ Although this was unnecessary in our patient, one must be prepared to create a pleural tent or use alternative space-eliminating maneuvers.

Finally, this case supports the reported association between marijuana smoking and giant bulla formation. ${ }^{5}$ Although our pa- tient had exposure to cigarette smoke and potentially provocative environmental agents, heavy use of marijuana may have contributed to bulla development. He was counseled regarding marijuana and cigarette cessation and protection against environmental exposures.

\section{References}

1. Fain WR, Conn JH, Campbell GD, et al. Excision of giant pulmonary emphysematous cyst-report of 20 cases without deaths. Surgery. 1967; 62:552-9.

2. Laros CD, Gelissen HJ, Bergstein PGM, et al. Bullectomy for giant bullae in emphysema. J Thorac Cardiovasc Surg. 1986;91:63-70.

3. Schipper PH, Meyers BF, Battafarano RJ, et al. Outcomes after resection of giant emphysematous bullae. Ann Thorac Surg. 2004;78:976-82.

4. Snider GL. Reduction pneumoplasty for giant bullous emphysema. Chest. 1996;109:540-8.

5. Johnson MK, Smith RP, Morrison D, Laszlo G, White RJ. Large lung bullae in marijuana smokers. Thorax. 2000;55:340-2. 